\title{
Anti-RA33 antibodies are present in a subset of patients with immune checkpoint inhibitor-induced inflammatory arthritis
}

Laura Cappelli ( $\triangle$ lcappel1@jhmi.edu )

Johns Hopkins School of Medicine https://orcid.org/0000-0003-2795-7059

Clifton O. Bingham III

Johns Hopkins School of Medicine

Patrick M. Forde

Johns Hopkins School of Medicine

Valsamo Anagnostou

Johns Hopkins School of Medicine

Julie Brahmer

Johns Hopkins School of Medicine

Evan J. Lipson

Johns Hopkins School of Medicine

Jennifer S. Mammen

Johns Hopkins School of Medicine

Megan Schollenberger

Johns Hopkins School of Medicine: Johns Hopkins University School of Medicine

Ami A. Shah

Johns Hopkins School of Medicine

Erika Darrah

Johns Hopkins School of Medicine

Research article

Keywords: inflammatory arthritis, immune checkpoint inhibitor, autoantibody

Posted Date: November 3rd, 2021

DOI: https://doi.org/10.21203/rs.3.rs-1017328/v1

License: (c) (1) This work is licensed under a Creative Commons Attribution 4.0 International License.

Read Full License 


\section{Abstract \\ Background}

Patients with inflammatory arthritis (IA) associated with immune checkpoint inhibitor (ICI) treatment for cancer are typically seronegative for anti-CCP antibodies and rheumatoid factor, but little is known about the presence of other autoantibodies described in early inflammatory arthritis in this patient population. We investigated the prevalence and characteristics of anti-RA33 antibodies in patients with ICI-induced IA.

\section{Methods}

Anti-RA33 ELISAs were performed on sera from four groups of patients: 79 with ICl-induced IA, 52 with rheumatoid arthritis (RA), 35 treated with ICls without IA during follow-up, and 50 healthy controls. AntiRA33 positivity and titer, clinical and demographic data were compared across groups.

\section{Results}

Anti-RA33 antibodies were found in 9/79 (11.4\%) patients with ICl-induced IA but in 0/35 patients treated with ICls who did not develop IA ( $0 \% ; \mathrm{p}=0.04)$. Of the 9 patients positive for anti-RA33, two had sera available from before ICI treatment; anti-RA33 antibodies were present in both pre-ICI treatment. In RA patients, $7.7 \%$ were positive for anti-RA33 antibodies as were $2 \%$ of healthy controls. In ICl-induced IA, anti-RA33 antibodies were associated with anti-CCP antibodies $(p=0.001)$. We found no statistically significant differences in other clinical characteristics in those with and without anti-RA33 antibodies, but we observed trends toward anti-RA33 antibodies being more common in women and those receiving prior radiation therapy.

\section{Conclusions}

Anti-RA33 antibodies are present in a subset of patients with ICl-induced IA and may be a biomarker for developing IA. Additional studies evaluating serial samples before and after ICI treatment will further establish the temporal relationship of these antibodies to IA development.

\section{Background}

Immune checkpoint inhibitors (ICls) improve survival across a variety of malignancies ${ }^{1}$. Currently FDAapproved ICls target regulatory molecules including cytotoxic lymphocyte antigen-4 (CTLA-4), programmed cell death protein 1 (PD-1), and programmed death ligand 1 (PD-L1) allowing for increased $T$ cell activation and anti-tumor immune responses. This class of cancer immunotherapy can cause excess immune activation and inflammation leading to clinical syndromes termed immune-related 
adverse events (irAEs) ${ }^{2}$. IrAEs may resemble rheumatic diseases such as inflammatory arthritis (IA), polymyalgia rheumatica, sicca syndrome, and myositis ${ }^{34}$.

Though rheumatic irAEs share features with traditional autoimmune rheumatic diseases, there are key differences in some clinical characteristics, trajectory, treatment, and biomarkers ${ }^{5}$. For example, traditional autoantibodies found in Sjogren's syndrome or myositis have not been detected in the majority of patients with sicca syndrome or myositis as an irAE ${ }^{6-9}$. Patients with ICl-induced sicca syndrome can have very different histology on minor salivary gland biopsy as compared to primary Sjogren's syndrome ${ }^{7}$. Also, patients with myositis as an irAE are more likely to develop concomitant myocarditis or myasthenia gravis than those with idiopathic inflammatory myopathies ${ }^{10}$.

$\mathrm{ICl}$-induced IA is the most common irAE encountered by rheumatologists ${ }^{4}$. It is a heterogeneous entity that can persist after cessation of ICI therapy ${ }^{11-13}$. There are clear similarities and differences between ICl-induced IA and other forms of IA such as rheumatoid arthritis (RA) and spondyloarthritis.

Musculoskeletal ultrasound has shown synovitis, tenosynovitis, and erosions typical of RA, but also enthesitis and enthesophytes more characteristic of spondyloarthritis ${ }^{14}$. Most patients with ICl-induced IA lack traditional autoantibodies associated with RA and are not positive for HLA-B27, a genetic marker for spondyloarthritis ${ }^{13}$. Patients with a reactive arthritis-like phenotype and axial inflammation have also been reported ${ }^{121516}$. ICl-induced IA has been treated with corticosteroids, DMARDs like hydroxychloroquine and methotrexate, and biologics including TNF-inhibitors and IL-6 receptor inhibitors ${ }^{12} 1718$.

Antibodies to hnRNP A2/B1, termed anti-RA33 antibodies, have been described in RA and undifferentiated inflammatory arthritis. A meta-analysis showed that anti-RA33 has high specificity $(0.90)$ for a diagnosis of RA but low sensitivity $(0.33)^{19}$. Although the RA33 antigen can be targeted in its native or citrullinated form, antibodies that prefer the native form of hnRNP A2/B1 have been detected in early RA and in patients with low erosion scores on imaging ${ }^{20}$. The presence of anti-RA33 antibodies targeting the native antigen in early RA and undifferentiated inflammatory arthritis and the paucity of antibodies to citrullinated antigens noted in patients with ICl-induced IA led us to hypothesize that antibodies to the native RA33 antigen could be present in ICl-induced IA. We aimed to test whether patients with ICl-induced IA had antibodies to RA33 and whether anti-RA33 antibodies were specific to ICl-treated patients who did versus did not develop IA as an irAE. We also sought to explore clinical phenotypes in patients with and without anti-RA33 antibodies.

\section{Methods}

\section{Inclusion and exclusion criteria for four study groups}

Four groups of patients were included in the study as described below. All patient biospecimens were collected after approval by the Johns Hopkins Institutional Review Board. 
1) ICl-induced IA ( $n=79)$. These patients were drawn from a prospective, longitudinal study of patients with rheumatic irAEs. Patients with at least one serum sample after rheumatologist diagnosis of IClinduced IA were included. A subset of these patients also had pre-ICI treatment sera that was tested for anti-RA33 antibodies.

2) Healthy control sera $(n=50)$ was obtained from volunteers who were 18 years of age or older, not pregnant, and did not have a history of autoimmune disease, cancer, or active HIV, tuberculosis, or hepatitis infection. They donated sera through an IRB-approved collection protocol.

3) Patients with rheumatoid arthritis (RA) ( $n=52)$ were participants in the Johns Hopkins Arthritis Center's longitudinal database. Clinical data were patient- and physician-reported and collected prospectively at the time of clinic visits. Patients had rheumatologist-diagnosed RA and were included if they had sera and clinical data available on the same date.

4) Sera from ICl-treated patients who did not develop IA $(n=35)$ were collected through the Johns Hopkins upper aerodigestive malignancy group's tissue collection protocol. This included patients with non-small cell lung cancer (NSCLC), small cell lung cancer, mesothelioma, head and neck squamous cell carcinoma, and poorly differentiated carcinoma. Patients treated with anti-PD-1, anti-PD-L1, anti-CTLA-4 agents or a combination of these therapies were included. The database for this study was queried for patients who did not have a diagnosis of ICl-induced IA, which was confirmed with medical record review.

\section{Anti-RA33 antibody assay}

Anti-RA33 antibodies were measured in serum diluted 1:100 using the IMTEC-RA33-Antibodies

ELISA kit for the Quantitative Determination of Anti-RA33-IgG Antibodies (\#ITC60015, IMETC) according to the manufacturer's instructions. The cut off for positivity was set at 3 standard deviations above the mean of the healthy control group.

\section{Clinical data collection for ICl induced IA and RA}

Patient- and physician-reported data are collected at each visit in the longitudinal study of rheumatic irAEs. For patients with ICl-induced IA, joint counts, patient and physician global ratings of disease activity, patient ratings of pain and stiffness, presence of other features on examination (e.g., enthesitis), laboratory, and imaging findings are recorded at each clinical evaluation.

For patients with RA in the longitudinal database, physician and patient reported outcomes were collected at the time of each clinic visit. Historical information about their RA including date of onset, imaging findings, autoantibody status, and treatments were also recorded in the database.

\section{Statistical analysis}

Descriptive statistics were calculated for demographic and clinical variables of the four patient groups. Chi-square tests were used to compare frequencies of anti-RA33 antibodies between the four groups. Student's t-tests or Wilcoxon rank sum tests were used to compare continuous variables in ICl-induced IA 
patients with and without anti-RA33 antibodies depending on the distribution of the variable. Chi-square tests were used to compare categorical variables in those positive and negative for anti-RA33.

\section{Results}

\section{Demographic features of included participants:}

Overall, 216 patients were tested for anti-RA33 antibodies; 79 patients had ICl-induced IA, 50 were healthy controls, 52 had RA, and 35 were treated with ICls without developing IA. The healthy control participants were the youngest group $(p<0.01)$. The percentage of female patients did not differ significantly by group (Table 1). The ICl-treated patients who did not develop IA had the highest prevalence of former and current smokers which was significantly different than smoking histories of patients with ICl-induced IA $(p<0.01)$. The ICl-treated patients without IA were also significantly older than those with IA $(p<0.01)$.

Table 1

Demographics and anti-RA33 results of 4 groups

\begin{tabular}{|c|c|c|c|c|}
\hline & $\begin{array}{l}\text { ICl-IA } \\
(\mathrm{N}=79)\end{array}$ & $\begin{array}{l}\text { Healthy } \\
\text { Controls } \\
(\mathrm{N}=50)\end{array}$ & $\begin{array}{l}\mathrm{RA} \\
(\mathrm{N}=52)\end{array}$ & $\begin{array}{l}\text { ICI Without IA } \\
(\mathrm{N}=35)\end{array}$ \\
\hline Age (years), Mean \pm SD & $60.4 \pm 14.2$ & $39.9 \pm 10.0 * \star \star$ & $57.9 \pm 12.6$ & $68.2 \pm 9.1^{\star \star \star}$ \\
\hline Female, N (\%) & $41(51.9)$ & $29(58)$ & $28(53.9)$ & $13(37.1)$ \\
\hline \multirow[t]{3}{*}{ Smoking History, N (\%) } & Never: 43 (58.8) & Never: 34 (68) & $\begin{array}{l}\text { Never: } 35 \\
(67.3)\end{array}$ & $\begin{array}{l}\text { Never: } 3 \text { (8.6) } \\
\star \star \star\end{array}$ \\
\hline & $\begin{array}{l}\text { Former: } 28 \\
(37.8)\end{array}$ & $\begin{array}{l}\text { Former: } 15 \\
(30)\end{array}$ & $\begin{array}{l}\text { Former: } 13 \\
\text { (25) }\end{array}$ & $\begin{array}{l}\text { Former: } 29 \\
(91.4)\end{array}$ \\
\hline & Current: 3 (4.5) & current: I (2) & $\begin{array}{l}\text { Current: } 4 \\
\text { (7.7) }\end{array}$ & Current: 3 (8.6) \\
\hline Anti-RA33 positive, N ( \%) & $9(11.4 \%)$ & $1(2 \%)$ * & $4(7.7 \%)$ & $0(0 \%)$ ** \\
\hline $\begin{array}{l}\text { Anti-RA33 titer, Median } \\
\text { (IQR) }\end{array}$ & $0.27(0,4.18)$ & $0.61(0,2.75)$ & $0(0,3.89)$ & $0(0,1.69)$ * \\
\hline
\end{tabular}

\section{Comparison of anti-RA33 frequencies and titer}

Of the 79 patients with ICl-induced IA, 9 had anti-RA33 antibodies at their first sample collection (11.4\%, Table 1). This was a larger percentage of anti-RA33 positivity than for healthy controls $(2 \%, p=0.05)$ and ICl-treated patients without IA $(0 \%, p=0.04)$. There was no statistically significant difference in anti-RA33 positivity between those with ICI-induced IA and RA $(7.7 \%, p=0.48)$. 
While there was no statistically significant difference between the groups (Table 1), patients with IClinduced IA who had detectable anti-RA33 antibodies had most of the higher titer measurements as demonstrated visually in Figure 1. Specifically, four out of five patients with antibody titer measurements over 50 units $/ \mathrm{mL}$ were in the ICl-IA group. For those above the cut-off for anti-RA33 positivity, patients with ICl-induced IA had a mean titer of 61.8 units and a median titer of 29.3 units, while patients with RA had a mean titer of 49.3 units and a median titer of 23.4 units.

\section{RA patients and anti-RA33}

We evaluated 52 patients with RA. The mean duration of RA at the time of sample was 9.9 years (SD 10.5). Of the 52 patients, 31 (59.6\%) had erosions on imaging, 34 had anti-CCP (65.4\%), 30 were positive for rheumatoid factor (57.7\%), and 32 had at least one shared epitope allele (61.5\%).

Of the 4 patients positive for anti-RA33 antibodies, three were female and one was male. Duration of RA at the time of sample ranged from 1 to 26 years. All four patients identified as Caucasian, were positive for anti-CCP, had at least one shared epitope allele, and were never smokers. Because few patients with RA in this cohort were positive for anti-RA33 antibodies, there were no statistically significant differences in clinical or demographic features from the overall population of RA patients tested.

\section{Clinical features of anti-RA33 positive and negative patients with ICl-induced IA}

Patients with and without anti-RA33 antibodies did not have significant differences in tumor type, immunotherapy regimen or prevalence of prior chemotherapy or radiation therapy, though the patients with anti-RA33 antibodies did have a numerically higher percentage of individuals who received prior radiation ( $55.6 \%$ vs. $31.4 \%, p=0.15$, Table 2$)$. However, people with anti-RA33 antibodies were significantly more likely to be positive for anti-CCP antibodies than anti-RA33 negative individuals ( $25 \%$ vs. $1.4 \%$, $p=0.001)$, but had a similar prevalence of rheumatoid factor and anti-nuclear antibodies $(p=0.54$ and 0.82 , respectively). The time to develop IA from ICI initiation was similar in both groups of patients, 189 days on average in the anti-RA33 positive group and 209 days in the anti-RA33 negative group $(p=0.79)$. Enthesitis was present in 25\% of patients with ICl-induced IA and did not differ based on anti-RA33 status (Table 2). Patients with and without anti-RA33 had similar ratings of pain, stiffness, disease activity and similar CDAl scores at their first rheumatology visit. Of patients seen in follow up at least 6 months after $\mathrm{ICl}$ cessation, $70.5 \%$ still had symptoms of IA or were on medications to control IA symptoms, and there were no differences in persistence of IA by anti-RA33 status. For all ICl-induced IA patients, $82.3 \%$ required corticosteroids, $32.9 \%$ csDMARDs and $17.7 \%$ biologics; there were no statistically significant differences in treatments required by anti-RA33 positivity (Table 2 ). 
Table 2

Clinical features of ICI-IA in RA33 positive and negative

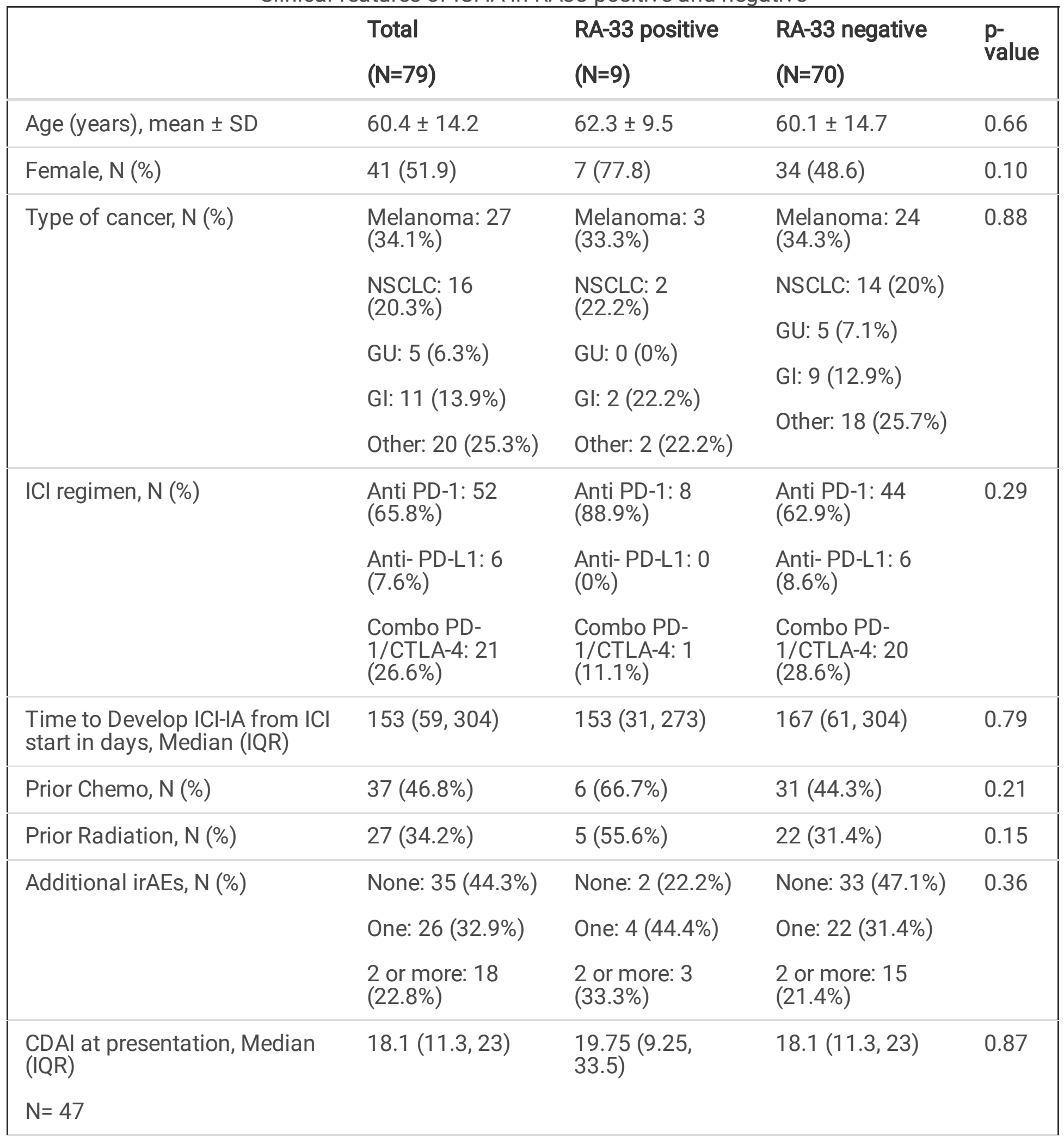

- Chi-square test for categorical variables, $T$ test for age, Wilcoxon Rank sum for other continuous variables. $\mathrm{RF}=$ rheumatoid factor, $\mathrm{ANA}=$ anti-nuclear antibodies, $\mathrm{cSDMARD}=$ conventional synthetic disease modifying anti-rheumatic drugs, VAS= 100 point visual analog scale 


\begin{tabular}{|c|c|c|c|c|}
\hline & $\begin{array}{l}\text { Total } \\
(\mathrm{N}=79)\end{array}$ & $\begin{array}{l}\text { RA-33 positive } \\
(\mathrm{N}=9)\end{array}$ & $\begin{array}{l}\text { RA-33 negative } \\
(\mathrm{N}=70)\end{array}$ & $\begin{array}{l}\mathrm{p}- \\
\text { value }\end{array}$ \\
\hline $\begin{array}{l}\text { Swollen joint count } \\
\text { Median (IQR) } \\
\mathrm{N}=72\end{array}$ & $6(3,10)$ & $4(2,9)$ & $6(3,11)$ & 0.73 \\
\hline $\begin{array}{l}\text { Patient Global } \\
\text { Median (IQR) } \\
\mathrm{N}=63\end{array}$ & $35(15,50)$ & $35(17,70)$ & $35(12,50)$ & 0.53 \\
\hline $\begin{array}{l}\text { Stiffness VAS, } \\
\text { Median (IQR) } \\
\mathrm{N}=67\end{array}$ & $50(33,75)$ & $70(45,75)$ & $50(30,75)$ & 0.41 \\
\hline $\begin{array}{l}\text { Pain VAS } \\
\text { Median (IQR) } \\
\mathrm{N}=68\end{array}$ & $50(21.5,75)$ & $71(20,75)$ & $50(23,70)$ & 0.33 \\
\hline Enthesitis, N (\%) & $20(25.3)$ & $2(22.2)$ & $18(25.7)$ & 0.82 \\
\hline Required corticosteroid, N (\%) & $65(82.3)$ & $7(77.8)$ & $58(82.9)$ & 0.71 \\
\hline Required csDMARD, N (\%) & $26(32.9)$ & $4(44.4)$ & $22(31.4)$ & 0.43 \\
\hline Required biologic, N (\%) & $14(17.7)$ & $2(22.2)$ & $12(17.1)$ & 0.71 \\
\hline $\begin{array}{l}\text { RF positive, } N(\%) \\
N=75\end{array}$ & $3(4)$ & $0(0)$ & $3(4.5)$ & 0.54 \\
\hline $\begin{array}{l}\text { CCP positive, } N(\%) \\
N=75\end{array}$ & $3(4)$ & $2(25)$ & $1(1.4)$ & 0.001 \\
\hline $\begin{array}{l}\text { ANA positive, } N(\%) \\
N=69\end{array}$ & $12(17.4 \%)$ & $1(14.2)$ & $11(17.7)$ & 0.82 \\
\hline $\begin{array}{l}\mathrm{ICl} \text { persistence }(6 \text { months after } \\
\mathrm{ICl} \text { cessation), } \mathrm{N}(\%) \\
\mathrm{N}=51\end{array}$ & $36(70.5)$ & $3(75)$ & $33(70)$ & 0.84 \\
\hline $\begin{array}{l}\text { - Chi-square test for categorical } \\
\text { variables. } \mathrm{RF}=\text { rheumatoid factc } \\
\text { disease modifying anti-rheuma }\end{array}$ & $\begin{array}{l}\text { riables, T test } \\
\text { ANA }=\text { anti-nuc } \\
\text { drugs, VAS }=1\end{array}$ & $\begin{array}{l}\text {, Wilcoxon Rar } \\
\text { tibodies, csDM } \\
\text { it visual analo }\end{array}$ & $\begin{array}{l}\text { for other con } \\
\text { conventional } \\
\text { e }\end{array}$ & $\begin{array}{l}\text { s } \\
\text { tic }\end{array}$ \\
\hline
\end{tabular}

\section{Anti-RA33 Pre-ICl treatment}


Pre-ICI treatment sera was available for 15 subjects with ICl-induced IA. Pre-treatment samples were collected within a month prior to ICI start. Of these 15, two had positive anti-RA33 antibodies after treatment. Both patients were positive for anti-RA33 before treatment started at similar levels as their post-ICI treatment levels. Interestingly, neither were positive for anti-CCP antibodies or rheumatoid factor, two antibodies which have previously been reported to be positive before ICI initiation in patients who develop ICl-induced IA ${ }^{21}$. The 13 other subjects were negative for anti-RA33 in both pre- and posttreatment samples; these subjects were also negative for anti-CCP and RF.

\section{Discussion}

This is the first evaluation of autoantibodies beyond anti-nuclear antibodies, anti-CCP, and rheumatoid factor in a cohort of patients with ICl-induced IA. Anti-RA33 antibodies were detected in 11.4\% of patients with ICl-induced IA at the time of their first rheumatology visit, whereas none of the ICl-treated controls who did not develop IA were positive, and only $7.7 \%$ of patients with established RA were positive. For two patients with ICl-induced IA that had sera available from before ICI treatment, anti-RA33 antibodies were present before ICI exposure. Anti-RA33 antibodies did not correlate with particular clinical features of ICIinduced IA, treatments required, or persistence of IA beyond ICI cessation.

In the last decade, there has been considerable interest in the relationship between autoimmune diseases and immune responses to cancer. Autoantibodies in scleroderma and myositis have been linked to immune responses to genetically altered proteins in certain tumors. For patients with scleroderma, antiRNA polymerase III antibodies, and cancer, mutations and loss of heterozygosity in the RNA polymerase III gene in the tumor have been reported; similar findings are seen with anti-TIF1Y antibodies and mutated TIF1Y in myositis 2223 . Given that patients with ICl-induced IA all have cancer, there is a question of whether this autoantibody represents an immune response to a tumor antigen. Indeed, several tumor types have been shown to overexpress RA33 including glioblastoma, hepatocellular carcinoma and nonsmall cell lung cancer ${ }^{24-26}$. However, the finding that anti-RA33 antibodies were not found in people who have cancer but develop other non-IA irAEs post-ICI treatment, suggests that there is some specificity for anti-RA33 antibodies and ICl-induced IA. Future studies are warranted to interrogate the connection between tumor antigen expression and arthritis in patients positive for anti-RA33 antibodies.

In addition to the novel findings of anti-RA33 antibodies in this patient population, the clinical data from the group of ICl-induced IA patients reinforces the observation that ICl-induced IA can be a late side effect, developing 6 months or longer after ICI initiation. This may partially explain the lack of recognition of ICIinduced IA in clinical trials and practice as not all patients live to that point in their cancer therapy and others may experience other irAEs or complications requiring treatment that obscure the detection of IA. In the group of 51 patients who had follow up at least 6 months after ICl cessation, IA was present in $70.6 \%$, a higher percentage than previously reported ${ }^{11}$. This is a selected group, as patients are more likely to return to rheumatology clinic or respond to research inquiries if they are symptomatic, but this observation still emphasizes a sizable population who need longitudinal rheumatologic care in managing their ICl-induced IA. 
A limitation of this study was that ICl-treated controls primarily had lung cancer as their tumor type and thus not representative of the full range of tumor types in patients with ICl-induced IA. Since RA33 expression has been observed in range of tumor types, future study of ICI-IA patients with various tumor types will be informative. A second limitation was that it was primarily cross-sectional in nature. We do not have a clear view of when anti-RA33 antibodies develop in the course of ICl-induced IA or how long they persist. That antibodies were present pre-ICl in both of the patients who were positive for anti-RA33 and had pre- $\mathrm{ICl}$ treatment sera available is interesting in terms of their role in pathogenesis. It is possible that, as has been reported in patients with anti-CCP antibodies ${ }^{21}$, there are patients with pre-clinical inflammatory arthritis and anti-RA33 antibodies who manifest clinical IA only after ICI treatment. If this is the case, then anti-RA33 may represent a risk factor for ICl-induced IA and could be used in estimating risk and identifying patients for more intensive screening and early intervention when they are treated with ICls. Future work can expand testing beyond this cohort to confirm the observation that patients who are treated with ICls and do not develop IA lack anti-RA33 antibodies.

\section{Conclusions}

Although ICl-induced IA is increasingly appreciated clinically, there is still little known about its immune pathogenesis. Evaluating immunological factors in ICl-induced IA that are associated with other forms of early IA, such as the presence of anti-RA33 antibodies, is one strategy for understanding etiology and defining treatment targets. The implications of anti-RA33 antibodies in ICl-induced IA are unclear. Future studies elucidating the temporal relationship of these antibodies to $\mathrm{ICl}$ treatment and validating the presence of anti-RA33 in ICl-induced IA in separate and larger cohorts will help determine the utility of testing for these antibodies in clinical care and their role in pathogenesis.

\section{Declarations}

Ethics approval: This study was approved by the Johns Hopkins Institutional Review Board.

Availability of data and materials: The datasets during and/or analysed during the current study available from the corresponding author on reasonable request.

Competing Interests: LCC, COB have received research funding from Bristol-Myers Squibb. JB has served on advisory boards for Bristol-Myers Squibb, Merck, Astra Zeneca and Regeneron and has received research funding from Bristol-Myers Squibb. VA has received research funding from Bristol-Myers Squibb and Astra Zeneca. PMF has received honoraria or consulting fees from Amgen, AstraZeneca, Bristol Myers Squibb, Delfi, Novartis, Janssen, Iteos, Sanofi, Genentech, F-Star, G1 therapeutics, Surface Oncology; research funding from AstraZeneca, BMS, Kyowa, Corvus, Novartis, and is a DSMB member for Flame and Polaris. EJL has received institutional grant/research support from Bristol-Myers Squibb, Merck and Sanofi/Regeneron, and has been a consultant for Array BioPharma, Bristol-Myers Squibb, Eisai, EMD Serono, Genentech, Macrogenics, Merck, Novartis, Odonate Therapeutics, OncoSec and Sanofi-Regeneron.MS, ED, AAS, and JSM have no competing interests to disclose.

Page $10 / 14$ 
Funding: The work was supported by National Institute for Musculoskeletal and Skin Disorders (K23AR075872, P30AR070254, R01AR073208), and Bristol-Myers Squibb.

\section{References}

1. Topalian SL, Drake CG, Pardoll DM. Immune checkpoint blockade: a common denominator approach to cancer therapy. Cancer cell 2015;27(4):450-61. doi: 10.1016/j.ccell.2015.03.001 [published Online First: 2015/04/11]

2. Postow MA, Sidlow R, Hellmann MD. Immune-Related Adverse Events Associated with Immune Checkpoint Blockade. The New England journal of medicine 2018;378(2):158-68. doi:

10.1056/NEJMra1703481 [published Online First: 2018/01/11]

3. Cappelli LC, Gutierrez AK, Bingham CO, 3rd, et al. Rheumatic and Musculoskeletal Immune-Related Adverse Events Due to Immune Checkpoint Inhibitors: A Systematic Review of the Literature. Arthritis care \& research 2017;69(11):1751-63. doi: 10.1002/acr.23177 [published Online First: 2016/12/21]

4. Abdel-Wahab N, Suarez-Almazor ME. Frequency and distribution of various rheumatic disorders associated with checkpoint inhibitor therapy. Rheumatology (Oxford, England) 2019;58(Suppl 7):vii40vii48. doi: 10.1093/rheumatology/kez297 [published Online First: 2019/12/10]

5. Calabrese LH, Calabrese C, Cappelli LC. Rheumatic immune-related adverse events from cancer immunotherapy. Nature reviews Rheumatology 2018 doi: 10.1038/s41584-018-0074-9 [published Online First: 2018/09/02]

6. Narvaez J, Juarez-Lopez P, J LL, et al. Rheumatic immune-related adverse events in patients on antiPD-1 inhibitors: Fasciitis with myositis syndrome as a new complication of immunotherapy. Autoimmunity reviews 2018;17(10):1040-45. doi: 10.1016/j.autrev.2018.05.002 [published Online First: 2018/08/14]

7. Warner BM, Baer AN, Lipson EJ, et al. Sicca Syndrome Associated with Immune Checkpoint Inhibitor Therapy. The oncologist 2019;24(9):1259-69. doi: 10.1634/theoncologist.2018-0823 [published Online First: 2019/04/19]

8. Touat M, Maisonobe T, Knauss S, et al. Immune checkpoint inhibitor-related myositis and myocarditis in patients with cancer. Neurology 2018;91(10):e985-e94. doi: 10.1212/wnl.0000000000006124 [published Online First: 2018/08/10]

9. Seki M, Uruha A, Ohnuki Y, et al. Inflammatory myopathy associated with PD-1 inhibitors. Journal of autoimmunity 2019;100:105-13. doi: 10.1016/j.jaut.2019.03.005 [published Online First: 2019/03/14]

10. Shelly S, Triplett JD, Pinto MV, et al. Immune checkpoint inhibitor-associated myopathy: a clinicoseropathologically distinct myopathy. Brain communications 2020;2(2):fcaa181. doi: 
10.1093/braincomms/fcaa181 [published Online First: 2020/12/12]

11. Braaten TJ, Brahmer JR, Forde PM, et al. Immune checkpoint inhibitor-induced inflammatory arthritis persists after immunotherapy cessation. Annals of the rheumatic diseases 2020;79(3):332-38. doi: 10.1136/annrheumdis-2019-216109 [published Online First: 2019/09/22]

12. Cappelli LC, Brahmer JR, Forde PM, et al. Clinical presentation of immune checkpoint inhibitorinduced inflammatory arthritis differs by immunotherapy regimen. Seminars in arthritis and rheumatism 2018;48(3):553-57. doi: 10.1016/j.semarthrit.2018.02.011 [published Online First: 2018/03/27]

13. Ghosh N, Tiongson MD, Stewart C, et al. Checkpoint Inhibitor-Associated Arthritis: A Systematic Review of Case Reports and Case Series. Journal of clinical rheumatology : practical reports on rheumatic \& musculoskeletal diseases 2020 doi: 10.1097/rhu.0000000000001370 [published Online First: 2020/04/30]

14. Albayda J, Dein E, Shah AA, et al. Sonographic Findings in Inflammatory Arthritis Secondary to Immune Checkpoint Inhibition: A Case Series. ACR open rheumatology 2019;1(5):303-07. doi:

10.1002/acr2.1026 [published Online First: 2019/11/30]

15. Bronstein Y, Ng CS, Hwu P, et al. Radiologic manifestations of immune-related adverse events in patients with metastatic melanoma undergoing anti-CTLA-4 antibody therapy. AJR Am J Roentgenol 2011;197(6):W992-w1000. doi: 10.2214/ajr.10.6198 [published Online First: 2011/11/24]

16. Cencini E, Bocchia M, Fabbri A. Nivolumab in relapsed/refractory Hodgkin lymphoma: towards a new treatment strategy? American journal of blood research 2021;11(3):261-65. [published Online First: 2021/07/30]

17. Kim ST, Tayar J, Trinh VA, et al. Successful treatment of arthritis induced by checkpoint inhibitors with tocilizumab: a case series. Annals of the rheumatic diseases 2017;76(12):2061-64. doi:

10.1136/annrheumdis-2017-211560 [published Online First: 2017/08/24]

18. Roberts J, Smylie M, Walker J, et al. Hydroxychloroquine is a safe and effective steroid-sparing agent for immune checkpoint inhibitor-induced inflammatory arthritis. Clinical rheumatology 2019;38(5):151319. doi: 10.1007/s10067-019-04451-2 [published Online First: 2019/02/01]

19. Yang $X$, Wang $M$, Zhang $X$, et al. Diagnostic accuracy of anti-RA33 antibody for rheumatoid arthritis: systematic review and meta-analysis. Clinical and experimental rheumatology 2016;34(3):539-47. [published Online First: 2016/04/07]

20. Konig MF, Giles JT, Nigrovic PA, et al. Antibodies to native and citrullinated RA33 (hnRNP A2/B1) challenge citrullination as the inciting principle underlying loss of tolerance in rheumatoid arthritis. Annals of the rheumatic diseases 2016;75(11):2022-28. doi: 10.1136/annrheumdis-2015-208529 [published Online First: 2016/02/13] 
21. Belkhir R, Burel SL, Dunogeant $L$, et al. Rheumatoid arthritis and polymyalgia rheumatica occurring after immune checkpoint inhibitor treatment. Annals of the rheumatic diseases 2017;76(10):1747-50. doi: 10.1136/annrheumdis-2017-211216 [published Online First: 2017/06/11]

22. Joseph CG, Darrah E, Shah AA, et al. Association of the autoimmune disease scleroderma with an immunologic response to cancer. Science (New York, NY) 2014;343(6167):152-7. doi:

10.1126/science.1246886 [published Online First: 2013/12/07]

23. Pinal-Fernandez I, Ferrer-Fabregas B, Trallero-Araguas E, et al. Tumour TIF1 mutations and loss of heterozygosity related to cancer-associated myositis. Rheumatology (Oxford, England) 2018;57(2):38896. doi: 10.1093/rheumatology/kex413 [published Online First: 2017/11/18]

24. Golan-Gerstl R, Cohen M, Shilo A, et al. Splicing factor hnRNP A2/B1 regulates tumor suppressor gene splicing and is an oncogenic driver in glioblastoma. Cancer research 2011;71(13):4464-72. doi: 10.1158/0008-5472.can-10-4410 [published Online First: 2011/05/19]

25. Shilo A, Ben Hur V, Denichenko P, et al. Splicing factor hnRNP A2 activates the Ras-MAPK-ERK pathway by controlling A-Raf splicing in hepatocellular carcinoma development. RNA (New York, NY) 2014;20(4):505-15. doi: 10.1261/rna.042259.113 [published Online First: 2014/02/28]

26. Zhou J, Nong L, Wloch M, et al. Expression of early lung cancer detection marker: hnRNP-A2/B1 and its relation to microsatellite alteration in non-small cell lung cancer. Lung cancer (Amsterdam, Netherlands) 2001;34(3):341-50. [published Online First: 2001/11/21]

\section{Figures}




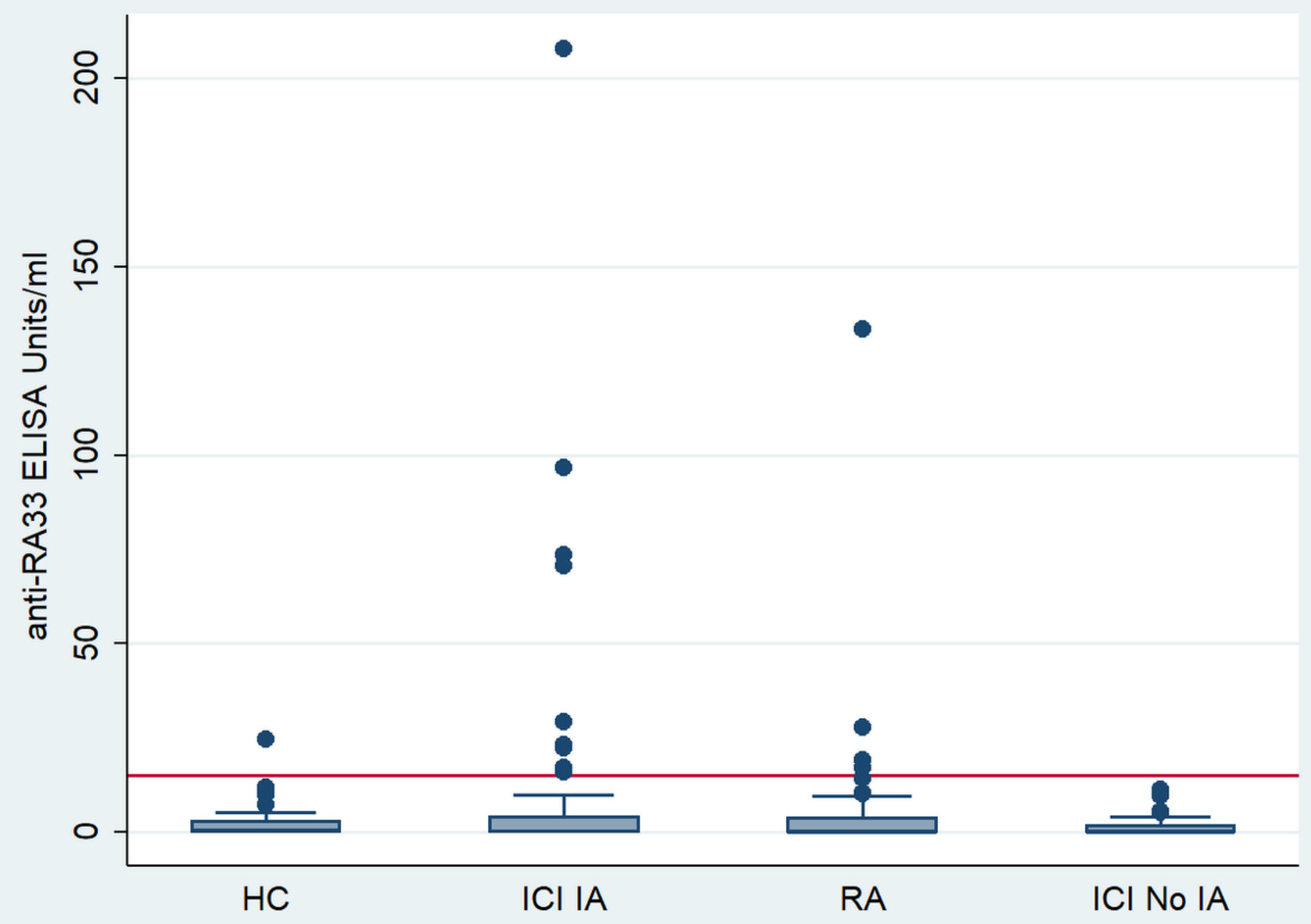

Figure 1

Anti-RA33 levels in ICl-induced Inflammatory arthritis (ICI IA), healthy controls (HC), Rheumatoid Arthritis (RA), and ICl-exposed patients without IA (ICI No-IA) 